\title{
Assessing the Effects of a Paired TBL Session and Patient Simulation on Pharmacy Student HIV Treatment Knowledge
}

Juanita A Draime, PharmD; Anna M Staudt, PharmD; Nicole Deitschmann, BSPS; Zachary Jenkins, PharmD, BCPS

Cedarville University, School of Pharmacy

\begin{abstract}
Description of the Problem: Pharmacists can play a crucial role in monitoring, counseling, and providing adherence checks across practice pharmacy settings; but they may not gain experience in this area until after graduating from pharmacy school.

Statement of Innovation: Students participated in an intentionally aligned team-based learning session followed by completion of an HIV patient treatment worksheet and an HIV patient care simulation. This sequence was assessed using the HIV Treatment Knowledge Scale.

Description of the Innovation: Second-year pharmacy students ( $N=48,98 \%$ response rate) participated in a baseline knowledge assessment before a four-hour HIV team-based learning (TBL) session, which included the use of an online HIV Patient Management Simulator. Students were administered the scale again post-session. Three days before the simulation, students had access to an HIV patient treatment worksheet that was required to be completed before the simulation. Ten days after the initial assessment, students participated in an HIV patient simulation where they proposed a new antiretroviral plan while also addressing monitoring, barriers, and maximizing adherence for the patient. Post-simulation, students were again administered the scale. Data were analyzed using descriptive statistics, Wilcoxon and paired t-tests, as appropriate.

Critical Analysis: A total of 48 second-year pharmacy students participated. HIV knowledge increased significantly post-TBL ( $p<0.001)$. Post-simulation, scores improved, but not significantly $(p=0.291)$. Knowledge on 15 of the 21 items on the HIV Treatment Knowledge Scale significantly improved from pre-TBL to post-simulation $(p \leq 0.025)$.
\end{abstract}

Next Steps: Future investigation should focus on the impact that HIV simulation training has on skills, abilities, confidence, and empathy.

Keywords: HIV, human immunodeficiency virus, patient simulation, education, pharmacy, active learning

\section{Description of the Problem}

Through hands-on learning and application of knowledge to unique situations, patient simulations are effective supplementations to didactic education. ${ }^{1}$ Currently, there is a paucity of evidence surrounding simulated HIV patient encounters for pharmacy students. Additionally, there is a need to improve HIV knowledge and comfort among pharmacists. ${ }^{2}$ One study demonstrated an increase of HIV knowledge for third-year medical students after patient simulation workshops. ${ }^{3-4}$ Therefore, a simulated patient encounter with an HIV positive patient was developed and implemented in an infectious diseases course.

\section{Statement of the Innovation}

Through hands-on learning and application of knowledge to unique situations, patient simulations are useful supplementations to didactic learning and aid in knowledge retention. Faculty involved in teaching the HIV content developed an intentional sequence of team-based learning,

Corresponding author: Juanita A Draime, PharmD

Cedarville University School of Pharmacy

251 North Main Street, Cedarville, OH 45314

Phone: 937-766-7475; Email: juanitaadraime@cedarville.edu using an online HIV Patient Management Simulator, ${ }^{5}$ and a patient simulation to allow students to apply their clinical knowledge and counseling skills. In addition, learning was assessed through pre-TBL, post-TBL and post-simulations administrations of the HIV Treatment Knowledge Scale.

\section{Description of the Innovation \\ Study participants}

The study was found to be exempt by the University's Institutional Review Board. Participants $(\mathrm{N}=48$ ) were secondyear PharmD students. This study was completed during the spring semester 2018 using a pre-/post-test study design in a required infectious disease module. (Figure 1 )

\section{HIV Treatment Knowledge Scale}

At the beginning of the three-week module, each student was given the HIV Treatment Knowledge Scale to complete in class via paper to establish a baseline of HIV therapy knowledge. The HIV Treatment Knowledge Scale is a 21-item scale) for measuring pharmacy student knowledge of HIV treatment issues through indicating if the answer is 'true' or 'false', or if they 'don't know.' ${ }^{6}$ Some validity evidence is available indicating good test-retest reliability $(r=0.83)$ and reliability (0.90). ${ }^{6}$ A total score is calculated with this tool by adding all correct answers and dividing by the total number of scale items, with a higher total score indicating greater HIV treatment knowledge. ${ }^{6}$ Scores range from zero to $21^{6}$ The validation study 
also showed that scores on the HIV Treatment Knowledge Scale correlated with general knowledge of HIV after a two-week test-retest, which allowed for assessment of knowledge in this study. ${ }^{6}$

\section{Team-based Learning Session}

TBL is one of the pedagogies used for the course with both students and instructors being well-versed in the implementation of TBL. Students are assigned at the beginning of each academic year to a TBL group that is used for all courses over the year. Each TBL group has between 5 to 6 students that were randomly assigned based on the following criteria: student StrengthsFinders results, gender and race/ethnicity. To keep teams balanced at least 2 students of race/ethnicity diversity where on each team as well as least 2 male students per team when possible.

Students engaged in a four-hour TBL session covering HIV. The pre-work consisted of approximately five hours of assigned reading covering HIV guidelines, including HIV background, pathophysiology, treatment, and monitoring parameters, as well as viewing online videos from YouTube related to how HIV works and medication mechanisms of action. During the session, students completed a 10-question individual readiness assessment test (iRAT) covering the pre-class material followed by an identical team readiness assessment test (tRAT). Students were given a total of 45 minutes to complete both the iRAT ( 20 minutes) and TRAT (25 minutes). During this time, students were not allowed to use any notes or other materials. After all teams had completed the tRAT, the questions and answers were reviewed by each team revealing their answer choices (i.e. simultaneous reporting) and classroom discussions on why answers were chosen. The instructor provided further clarification for any questions not understood. Students then listened to a mini-lecture covering HIV diagnosis, assessment, treatment, monitoring, and adherence for reinforcement. In the last two hours of the class, after the mini-lecture, students engaged in a team-based application exercise using an online HIV Patient Management Simulator. ${ }^{5}$ This interactive simulation had a total of six scenarios where students were asked to choose the most appropriate treatment and monitoring options for patients based on adherence factors, laboratory values, side effects, comorbidities, and medication interactions. The simulated cases included a patient with a new HIV diagnosis regarding initial HIV therapy, a patient requiring adjustment of their HIV regimen due to complications from therapy, patients with barriers to therapy, and a patient requiring management of an opportunistic infection. Students were instructed to complete as many scenarios as possible within the time given (1.25 hours). During the last 45 minutes, the scenarios and appropriate responses were reviewed with student participation in explaining the answers chosen and instructor providing clarifications as needed. Afterward, students were administered the HIV Treatment Knowledge Scale in class via paper.

\section{Patient Care Simulation}

Ten days after initial assessment and three days post-TBL session, students participated in an HIV patient care simulation. The week prior to the simulation, students were provided the patient case, as well as instructions for the simulation. The patient case consisted of a patient diagnosed with HIV two years prior that had not received treatment. The patient had oropharyngeal and esophageal candidiasis, as well as a decreased CD4 count and increased HIV viral load. The students were expected to counsel the patient on new therapies for HIV and candidiasis. Students were required to complete an HIV patient treatment worksheet that they turned in prior to interacting with the patient. The patient treatment worksheet required students to choose the most appropriate treatments for the patient's candidiasis, as well as their uncontrolled HIV. Variables that were assessed from the worksheet included: pharmacologic treatment suggestions for ART, explanations of surrogate markers and use in monitoring HIV, and explanations of any monitoring (clinical \& lab) that the patient needs based on therapy choice. Following their assessment, students defined the drug, dose, schedule, duration of therapy, side effects, and other important counseling points for each treatment.

During the simulation, students were placed in the role of an Advanced Pharmacy Practice Experience (APPE) student in an HIV clinic that had been instructed to discuss their plan with the patient. During the simulation, students were not permitted to take notes or use electronic devices. Students had 15 minutes to individually counsel the patient on the following:

1. An appropriate antiretroviral regimen for the given patient (drug, dosage, schedule and duration of therapy, major side effects).

2. Any monitoring (clinical \& laboratory) that the patient would need to have completed.

3. Surrogate markers and their use in monitoring HIV disease.

4. An appropriate treatment regimen for the patient's oropharyngeal candidiasis opportunistic infection (drug, dosage, schedule and duration of therapy).

5. Potential barriers to medication adherence and strategies to overcome these barriers and maximize treatment adherence.

The patient simulation was conducted in the pharmacy simulation clinic. Each individual patient counseling session was video-recorded for use in assessing student performance. Course faculty watched the videos to assess each student using a rubric that assessed student knowledge based on the five objectives of the simulation, plus patient interaction skills (i.e. closure and teach back, pace and flow) using a 4-point Likert scale (i.e., Unsatisfactory, Needs Development, Satisfactory, and Commendable) (available on request) The patients for the counseling simulation were played by faculty, residents or 
Advanced Pharmacy Practice Experience (APPE) students and were given a role-play guide to ensure consistency between encounters. The patients also scored the students on their patient counseling skills (i.e. word use, professionalism, empathy) using a 4-point Likert Scale. At the end of the simulation, students completed the HIV Treatment Knowledge Scale a third time via a paper copy.(Figure 1).

\section{Findings}

Data were collected and de-identified prior to analysis, and all surveys were double-keyed to ensure accuracy of entry. Data were analyzed in SPSS v. 25.0 (IBM Corp., Armonk, NY). An $a$ priori $\mathrm{a}=0.05$ was used for statistical significance. Descriptive statistics and a chi-square analysis were utilized to evaluate differences in demographic data.

There was a total of 48 second-year professional pharmacy students who participated in the study (18 male, 30 female). There were no significant differences in HIV treatment knowledge based on gender or ethnicity. There was a significant difference between total correct responses from pre-TBL to post-TBL and pre-TBL to post-simulation $(p<0.001)$, but not significantly from post-TBL to post-simulation $(p=0.291)$.

Table 1 provides the total response correct based on each item. Total correct responses increased significantly from pre-TBL to post-TBL on 13 of the 21 survey items $(p<0.05)$, although no significant differences were observed from post-TBL to postsimulation. Knowledge on 15 of the 21 items on the HIV Treatment Knowledge Scale significantly improved from preTBL to post-simulation $(p \leq 0.025)$. Item numbers 5 and 13 had a significant increase in knowledge only from pre-TBL to postsimulation. Correct responses on 16 of the 21 items on the HIV Treatment Knowledge Scale increased from post-TBL to postsimulation, although not significantly.

\section{Critical Analysis}

The results of this study suggest that the TBL session produced an increase in HIV knowledge, which was sustained after completing a simulation experience. Although there was no statistically significant difference from post-TBL to postsimulation, there was a trend in knowledge improvement for 16 of the 21 items on the HIV Treatment Knowledge Scale. These findings may be incidental; however, the change may also not have been observable to be statistically significant due to a small sample size.

Other studies have demonstrated an increase in student knowledge following a simulation. In a medication adherence study by Sutton and colleagues, medical students took part in simulated highly active antiretroviral therapy (HAART). Students valued the experience and significantly improved their insight, attitude, and recognition towards medication adherence and its related challenges. ${ }^{7}$ In a study by Serag-Bolos and colleagues, an oncology simulation significantly improved pharmacy student therapeutic knowledge. ${ }^{4}$ One way to use a simulation event alongside of a TBL session that would allow for a better reinforcement of student knowledge would be to have a debriefing session with the students immediately following the simulation with a faculty member to allow for reinforcement or correction of observed concepts and skills. Additionally, the simulation event could be designed in a manner that would reinforced correct concepts that would help in reinforcement of knowledge learned during the didactic session.

The knowledge test that was utilized in this study was neither designed nor intended to capture skills-based outcomes. The patient care simulation was an application of the knowledge students have acquired during their preparation for and participation in the TBL session. This activity addresses the Accreditation Council for Pharmacy Education (ACPE) Standards 3 and 10, as well as the Center for the Advancement of Pharmaceutical Education (CAPE) Outcomes 3 and $4 .{ }^{8,9}$ Both the ACPE Standards and CAPE Outcomes recognize the clear and significant role of communication on patient care. This simulation allows the students to engage in active learning while practicing communication skills. While this study was not mapped to Entrustable Professional Activity (EPA) domains or the Pharmacists' Patient Care Process (PPCP), the simulation could be beneficial in meeting such outcomes and in emulating the PPCP, as students worked through collecting information, assessing information, planning care, implementing the plan, and discussing monitoring and follow-up.

To better assess student development, a scale to assess EPAs and/or the PCPP can be utilized in future research, as the treatment knowledge scale does not measure student development. Another limitation was faculty and students played the patient role without stringent guidelines regarding patient sexuality and how to respond to questions or with questions to student learners. Actors may provide a more realistic patient role in simulations, as they would more closely portray an actual patient. ${ }^{10}$

\section{Next Steps}

Similar activities at other institutions may assist in preparing students for future practice. However, further research should examine the impact on skills and abilities, student confidence, and student empathy through this experience. In the future, we plan to use the online National HIV curriculum to better prepare students for the TBL session through course modules and self-study cases.

Acknowledgements: Dr. Louise Balfour and colleagues for allowing the use of the HIV Treatment Knowledge Scale.

Funding/Support: This work was supported by Cedarville University School of Pharmacy research grants.

Conflicts of Interest: None 


\section{REFERENCES}

1. Schafer JJ, Gill TK, Sherman EM, McNicholl IR. ASHP guidelines on pharmacist involvement in HIV care. Am $J$ Health Syst Pharm. 2016:e72. DOI: 10.2146/ajhp150623

2. Davis Pate M, Shell AT, King SR. Assessing pharmacists' perspectives of HIV and the care of HIVinfected patients in Alabama. Pharm Pract (Granada). 2012;10:188-193. DOI: 10.4321/s188636552012000400002

3. Haist SA, Lineberry MJ, Griffith $\mathrm{CH}$, Hoellein AR, Talente GM, Wilson JF. Sexual history inquiry and HIV counseling: Improving clinical skills and medical knowledge through an interactive workshop utilizing standardized patients. Adv Health Sci Educ. 2008;13:427-434. DOI: 10.1007/s10459-006-9053-z 4.

4. Serag-Bolos ES, Chudow M, Perkins J, Patel RV. Enhancing Student Knowledge Through a Comprehensive Oncology Simulation. Am J Pharm Educ. 2018;82(3):6245. DOI: 10.5688/ajpe6245

5. Daar ES, Elion RA. Virtual HIV Patient Management Simulator: Translating Optimal Treatment Strategies into Practice via a Virtual Clinical Training Environment. https://alivesim.com/cme/vindico-hivsim. Published December 20, 2016. Accessed January 7, 2020.
6. Balfour L, Kowal J, Tasca GA, et al. Development and psychometric validation of the HIV Treatment Knowledge Scale. AIDS Care. 2007;19:1141-1148. DOI: 10.1080/09540120701352241

7. Sutton EL, Transue ER, Comes S, Paauw DS. Placebo HAART regimen as a method for teaching medication adherence issues to students. J Gen Intern Med. 2005;20(6):541-545. DOI: 10.1111/j.15251497.2005.0096.x

8. Accreditation Council for Pharmacy Education. Accreditation standards and key elements for the professional program leading to the doctor of pharmacy degree: Standards 2016. https://www.acpeaccredit.org/pdf/Standards2016FINAL.pdf. Published February 2, 2015. Accessed November 29, 2018.

9. Medina MS, Plaza CM, Stowe CD, et al. Center for the Advancement of Pharmacy Education 2013 educational outcomes. Am J Pharm Educ. 2013;77:162. DOI: 10.5688/ajpe778162

10. Bell SK, Pascucci R, Fancy K, Coleman K, Zurakowski D, Meyer EC. The educational value of improvisational actors to teach communication and relational skills: perspectives of interprofessional learners, faculty, and actors. Patient Educ Couns. 2014;96:381-388. DOI: 10.1016/j.pec.2014.07.001

Figure 1: Timeline of the Intervention
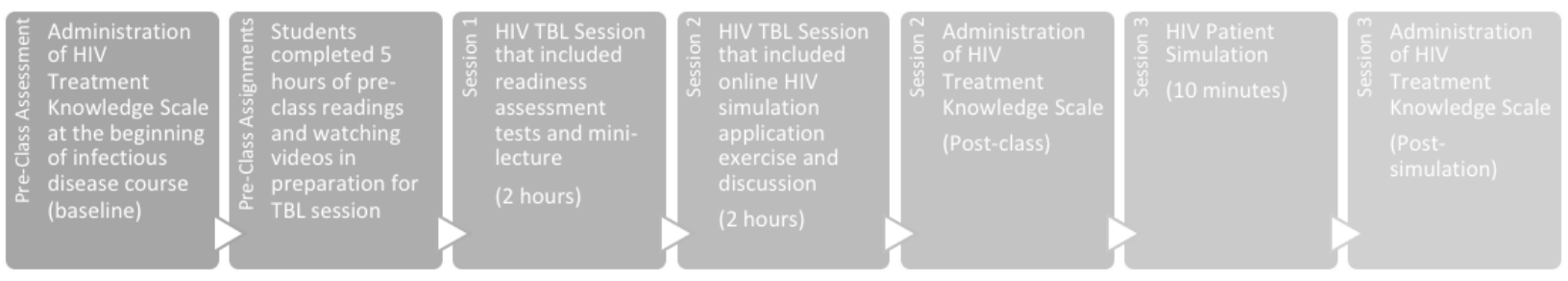
Table 1. Differences between correct responses on each HIV Treatment Knowledge Scale Item

\begin{tabular}{|c|c|c|c|c|c|c|}
\hline \multirow[b]{2}{*}{ Scale Item } & \multicolumn{3}{|c|}{$\begin{array}{c}\text { Total Correct Responses } \\
\text { N(\%) }\end{array}$} & \multicolumn{3}{|c|}{ p-values } \\
\hline & $\begin{array}{l}\text { Pre- } \\
\text { TBL }\end{array}$ & $\begin{array}{l}\text { Post- } \\
\text { TBL }\end{array}$ & $\begin{array}{l}\text { Post- } \\
\text { Sim }\end{array}$ & $\begin{array}{c}\text { Pre-TBL } \\
\text { vs Post- } \\
\text { TBL } \\
\end{array}$ & $\begin{array}{l}\text { Post TBL } \\
\text { vs Post- } \\
\text { Sim }\end{array}$ & $\begin{array}{c}\text { Pre-TBL } \\
\text { vs Post- } \\
\text { Sim } \\
\end{array}$ \\
\hline $\begin{array}{l}\text { 1. Once the HIV viral load results are "undetectable," HIV } \\
\text { medications should be stopped (F) }\end{array}$ & $\begin{array}{c}36 \\
(75 \%) \\
\end{array}$ & $\begin{array}{c}47 \\
(98 \%)\end{array}$ & $\begin{array}{c}48 \\
(100 \%) \\
\end{array}$ & 0.011 & 1.00 & 0.010 \\
\hline $\begin{array}{l}\text { 2. If HIV medications are not taken at the right time of day, HIV } \\
\text { drug resistance can occur ( } \mathrm{T} \text { ) }\end{array}$ & $\begin{array}{c}18 \\
(36 \%)\end{array}$ & $\begin{array}{c}23 \\
(48 \%)\end{array}$ & $\begin{array}{c}17 \\
(35 \%)\end{array}$ & 0.152 & 0.665 & 0.220 \\
\hline $\begin{array}{l}\text { 3. HIV is cured when the HIV viral load blood test result is } \\
\text { "undetectable" (F) }\end{array}$ & $\begin{array}{c}33 \\
(69 \%)\end{array}$ & $\begin{array}{c}46 \\
(96 \%)\end{array}$ & $\begin{array}{c}48 \\
(100 \%)\end{array}$ & 0.002 & 0.317 & 0.001 \\
\hline $\begin{array}{l}\text { 4. Condoms during sex are not needed when the HIV viral load } \\
\text { blood test results are at "undetectable" levels (F) }\end{array}$ & $\begin{array}{c}43 \\
(90 \%)\end{array}$ & $\begin{array}{c}47 \\
(98 \%)\end{array}$ & $\begin{array}{c}47 \\
(98 \%) \\
\end{array}$ & 0.046 & 0.317 & 0.025 \\
\hline $\begin{array}{l}\text { 5. It is better to take a half dose of the HIV medications than } \\
\text { stopping the HIV combination medications completely (F) }\end{array}$ & $\begin{array}{c}14 \\
(29 \%)\end{array}$ & $\begin{array}{c}21 \\
(44 \%)\end{array}$ & $\begin{array}{c}26 \\
(54 \%)\end{array}$ & 0.129 & 0.199 & 0.004 \\
\hline 6. One can get infected with a drug resistant type of HIV (T) & $\begin{array}{c}29 \\
(60 \%)\end{array}$ & $\begin{array}{c}41 \\
(85 \%)\end{array}$ & $\begin{array}{c}37 \\
(77 \%)\end{array}$ & 0.001 & 0.258 & 0.025 \\
\hline $\begin{array}{l}\text { 7. HIV medications can cause unpleasant side effects (e.g. } \\
\text { nausea, diarrhea, vomiting) (T) }\end{array}$ & $\begin{array}{c}45 \\
(94 \%)\end{array}$ & $\begin{array}{c}47 \\
(98 \%)\end{array}$ & $\begin{array}{c}45 \\
(94 \%)\end{array}$ & 0.157 & 0.83 & 0.679 \\
\hline $\begin{array}{l}\text { 8. If sexual partners are both HIV+ condoms are no longer } \\
\text { needed (F) }\end{array}$ & $\begin{array}{c}26 \\
(54 \%)\end{array}$ & $\begin{array}{c}41 \\
(85 \%)\end{array}$ & $\begin{array}{c}42 \\
(88 \%)\end{array}$ & 0.011 & 1.00 & 0.008 \\
\hline $\begin{array}{l}\text { 9. Treatments are available to reduce HIV medication side } \\
\text { effects (T) }\end{array}$ & $\begin{array}{c}36 \\
(75 \%)\end{array}$ & $\begin{array}{c}38 \\
(79 \%)\end{array}$ & $\begin{array}{c}44 \\
(92 \%)\end{array}$ & 0.182 & 0.189 & 0.051 \\
\hline $\begin{array}{l}\text { 10. Recreational drugs (e.g. ecstasy) can affect the } \\
\text { effectiveness of HIV medications ( } T \text { ) }\end{array}$ & $\begin{array}{c}35 \\
(73 \%) \\
\end{array}$ & $\begin{array}{c}38 \\
(79 \%) \\
\end{array}$ & $\begin{array}{c}40 \\
(83 \%)\end{array}$ & 0.330 & 0.763 & 0.207 \\
\hline $\begin{array}{l}\text { 11. Providing HIV medications to a pregnant woman reduces } \\
\text { the baby's risk of being infected with HIV }(T)\end{array}$ & $\begin{array}{c}22 \\
(46 \%)\end{array}$ & $\begin{array}{c}46 \\
(96 \%)\end{array}$ & $\begin{array}{c}47 \\
(98 \%)\end{array}$ & $<0.001$ & 0.655 & $<0.001$ \\
\hline $\begin{array}{l}\text { 12. There currently exists an HIV vaccine that prevents HIV } \\
\text { infection (F) }\end{array}$ & $\begin{array}{c}37 \\
(77 \%) \\
\end{array}$ & $\begin{array}{c}42 \\
(88 \%)\end{array}$ & $\begin{array}{c}40 \\
(83 \%)\end{array}$ & 0.782 & 0.157 & 0.166 \\
\hline $\begin{array}{l}\text { 13. HIV medications can be taken at a different time of day on } \\
\text { weekends or holidays (F) }\end{array}$ & $\begin{array}{c}33 \\
(69 \%) \\
\end{array}$ & $\begin{array}{c}33 \\
(69 \%) \\
\end{array}$ & $\begin{array}{c}37 \\
(77 \%) \\
\end{array}$ & 0.275 & 0.079 & 0.005 \\
\hline $\begin{array}{l}\text { 14. Over-the-counter herbal pills (e.g., St. John's Wort) could } \\
\text { make HIV medications less effective (T) }\end{array}$ & $\begin{array}{c}33 \\
(69 \%)\end{array}$ & $\begin{array}{c}43 \\
(90 \%)\end{array}$ & $\begin{array}{c}44 \\
(92 \%)\end{array}$ & 0.010 & 0.334 & 0.002 \\
\hline $\begin{array}{l}\text { 15. It is best to stop HIV medications as soon as you feel better } \\
\text { (F) }\end{array}$ & $\begin{array}{c}45 \\
(94 \%) \\
\end{array}$ & $\begin{array}{c}47 \\
(98 \%)\end{array}$ & $\begin{array}{c}48 \\
(100 \%) \\
\end{array}$ & 1.00 & 1.00 & 1.00 \\
\hline $\begin{array}{l}\text { 16. Missing a few doses of HIV pills can increase the amount of } \\
\text { HIV virus in the body }(T)\end{array}$ & $\begin{array}{c}25 \\
(52 \%)\end{array}$ & $\begin{array}{c}44 \\
(92 \%)\end{array}$ & $\begin{array}{c}45 \\
(94 \%)\end{array}$ & $<0.001$ & 0.705 & $<0.001$ \\
\hline $\begin{array}{l}\text { 17. After a few months, it becomes less important to take HIV } \\
\text { medications at the right time of day (F) }\end{array}$ & $\begin{array}{c}35 \\
(73 \%)\end{array}$ & $\begin{array}{c}40 \\
(83 \%)\end{array}$ & $\begin{array}{c}45 \\
(94 \%)\end{array}$ & 0.035 & 0.206 & 0.002 \\
\hline $\begin{array}{l}\text { 18. HIV medications help the body's immune system get } \\
\text { stronger (CD4 increase) (T) }\end{array}$ & $\begin{array}{c}12 \\
(25 \%)\end{array}$ & $\begin{array}{c}39 \\
(81 \%)\end{array}$ & $\begin{array}{c}43 \\
(90 \%)\end{array}$ & $<0.001$ & 0.248 & $<0.001$ \\
\hline $\begin{array}{l}\text { 19. When HIV medications work well, the HIV viral load } \\
\text { increases (F) }\end{array}$ & $\begin{array}{c}37 \\
(77 \%)\end{array}$ & $\begin{array}{c}46 \\
(96 \%)\end{array}$ & $\begin{array}{c}45 \\
(94 \%) \\
\end{array}$ & 0.002 & 0.317 & $<0.001$ \\
\hline $\begin{array}{l}\text { 20. Taking antibiotic medication protects a person from getting } \\
\text { infected with HIV (F) }\end{array}$ & $\begin{array}{c}36 \\
(75 \%)\end{array}$ & $\begin{array}{c}41 \\
(81 \%)\end{array}$ & $\begin{array}{c}44 \\
(92 \%)\end{array}$ & 0.005 & 0.755 & 0.002 \\
\hline $\begin{array}{l}\text { 21. Physical exercise (e.g., yoga, tai chi) can help reduce stress } \\
\text { levels in HIV patients }(T)\end{array}$ & $\begin{array}{c}39 \\
(81 \%)\end{array}$ & $\begin{array}{c}46 \\
(96 \%)\end{array}$ & $\begin{array}{c}47 \\
(98 \%)\end{array}$ & 0.008 & 0.317 & 0.011 \\
\hline
\end{tabular}

Note: The correct answer is indicated by $\mathrm{T}=$ True or $\mathrm{F}=$ False. Percentages are rounded to the nearest whole number. 